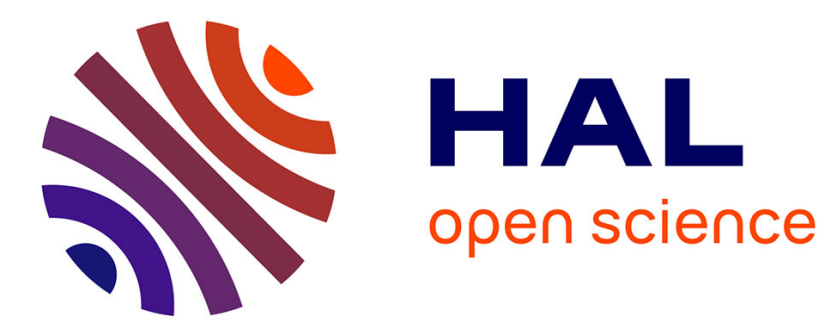

\title{
Modular biomimetic drug delivery systems
}

Christine Vauthier, Denis Labarre

\section{To cite this version:}

Christine Vauthier, Denis Labarre. Modular biomimetic drug delivery systems. Journal of Drug Delivery Science and Technology, 2008, 18 (1), pp.59-68. 10.1016/S1773-2247(08)50008-6 . hal03199968

\section{HAL Id: hal-03199968 https://hal.science/hal-03199968}

Submitted on 16 Apr 2021

HAL is a multi-disciplinary open access archive for the deposit and dissemination of scientific research documents, whether they are published or not. The documents may come from teaching and research institutions in France or abroad, or from public or private research centers.
L'archive ouverte pluridisciplinaire HAL, est destinée au dépôt et à la diffusion de documents scientifiques de niveau recherche, publiés ou non, émanant des établissements d'enseignement et de recherche français ou étrangers, des laboratoires publics ou privés. 


\title{
Modular biomimetic drug delivery systems
}

\author{
C. Vauthier*, D. Labarre \\ Physicochimie, Pharmacotechnie et Biopharmacie, Université Paris-Sud, CNRS UMR 8612, 92296 Châtenay- \\ Malabry, France
}

Received 20 November 2007, accepted for publication 4 January 2008.

Published in: J. DRUG DEL. SCI. TECH. 2008;18(1):59-68. https://doi.org/10.1016/S17732247(08)50008-6.

\begin{abstract}
${ }^{*}$ Correspondence:
Christine Vauthier. Physicochimie, Pharmacotechnie et Biopharmacie, Université Paris-Sud, CNRS UMR 8612, 92296 Châtenay-Malabry, France. christine.vauthier@u-psud.fr
\end{abstract}

\begin{abstract}
New treatments which may involve poorly soluble drugs, easy biodegradable molecules and drugs endowed with systemic toxicity need highly specific delivery, i.e. targeting. Nanocarriers are small enough drug delivery devices which can serve this purpose. Their design must meet with the constraints of the in vivo environments. Sophisticated strategies are required to deliver intact drugs into the cytoplasm of the targeted cells. Some bacteria and viruses have acquired such capabilities. Mimicking these pathogenic invaders for therapeutic purposes has been developed through biomimetic strategies. This paper attempts to review the integration of biomimetic strategies into domains of application of smart drug nanocarriers. Improving performance of vaccines by biomimetic antigen-presenting devices, precision of drug delivery by modulating drug biodistribution through modification of the surface of nanocarriers and release to the target site by integrating stimuli responding polymers are presented.
\end{abstract}

Key words: Vaccine adjuvant - Antigen-presenting device - Biodistribution - Drug release Polysaccharide - Stimuli-responsive system - Biomimetic - Nanoparticle - Liposome - Polymer micelle - Polymersome 


\section{INTRODUCTION}

Over the last thirty years, considerable efforts have been made to develop new types of drug delivery systems for improving the efficacy and specificity of treatments of serious diseases. A new era has started by the introduction of nanotechnology which makes it possible to produce small drug delivery devices theoretically capable of being diffused in the body and carrying the loaded drug down to target organs. So far, several platforms have emerged making considerable improvements of efficacy and precision of treatments possible and solving difficulties for the delivery of poorly soluble drugs, easy biodegradable molecules and therapeutic compounds with high systemic toxicity [1-9].

Basically, the different drug delivery nanotechnologies developed until now can be divided into two categories, whether they are existing biological entities diverted as drug carriers, e.g. inactivated viruses, ghost of red blood cells and bacteria and low density lipoproteins, or artificial constructs [1015]. The latter category has attracted much more work because they are considered to be safer for in vivo uses. Progresses in polymer chemistry and in colloid science have greatly contributed to their development as well as understanding amphiphilic copolymers behavior and macromolecule selfassembly phenomenon $[4,8,16-22]$.

Generally, drug carriers should hold various properties such as being capable of being loaded with a drug, possessing a very precise biodistribution and drug presentation to the target cells, delivering the drug with a defined delivery pattern and finally biodegrading into nontoxic products capable of being eliminated via natural means. The success of drug delivery can also be greatly affected by the way the device interacts with the biological surroundings encountered after in vivo administration. Finally, these interactions determine the performance of the system and its in vivo fate including the specificity of the drug targeting. To design such complex systems, several approaches have suggested integrating biomimetic methodologies [19, 23-26].

This paper attempts to review the different strategies integrating biomimetic methodologies to design drug carrier nanotechnology. The first part presents the design of antigen-presenting devices as new formulation tools for vaccines. It shows the integration of a biomimetic approach to build versatile nanotechnologies to present antigens in the correct way to immune cells, by mimicking viruses. The second part focuses on the design of drug delivery devices made of polymers whose surfaces are camouflaged by using a biomimetic approach. This part of the review shows methods that can be used to coat polymer nanoparticles with polysaccharides and how this can be applied to modulate their surface properties and interactions with biological media. Finally, the last part summarizes the recent developments in nanosystems integrating polymeric stimuli responding materials. This will give a more prospective view of the integration of another biomimetic-based methodology suggested to program and control the release of a drug associated with drug carriers.

\section{VACCINES}

A first field concerned by the application of biomimetic methodologies is the formulation of adjuvants used in vaccines for the prophylaxis of infectious diseases. Indeed, a key problem in vaccinology is the way antigens are presented to antigen-presenting cells such as dendritic cells and macrophages. The main role of the adjuvant added to formulations is to achieve presentation of the antigen to the immune system. The need to have efficient adjuvants is nowadays reinforced because most of the antigens entering the formulation of vaccines are synthetic proteins or peptides for safety reasons [16, $17,27,28]$. These antigens are prepared from recombinant proteins which replace the whole pathogens, or the inactivated subunits found in the traditional vaccines. Recombinant peptide and 
protein antigens are generally less immunogenic than the corresponding crude inactivated microorganism used in the old vaccine formulations $[29,30]$. In addition, all molecules of peptidic nature are difficult to administer in vivo because they are unstable in biological fluids and barely diffuse through biological barriers [31].

To overcome these drawbacks, it has been suggested to reconsider the way adjuvants are designed. To make the development of new antigen-presenting methods possible, new strategies started to utilize biomimetic approaches. Basically, proposals were made to build artificial viral particles presenting the antigen in the same way that it occurs on the surface of natural viruses. This was made possible due to progresses in immunology, biology, virology, and microbiology over the last thirty years which provided better understanding of the immune system. Moreover, our improved understanding of self-assembling mechanisms of lipids and proteins has made it possible to produce vesicles for reconstituting empty viral capsides $[16,17,29,32,33]$. For instance, nanotechnologies used for liposomes were rapidly integrated into this move because they provided a method for the reconstitution of adjuvants resembling the lipidic envelope of enveloped viruses. Virosomes, which are a recent technology platform, consist in liposome carriers for antigens (Figure $1 A$ ). They are already marketed as injectable vaccines against viruses responsible for major health threats in humans including hepatitis, e.g. Epaxal ${ }^{\circledR}$, and influenza, e.g. Inflexal ${ }^{\circledR}$ (Berna Biotech, Zurich, Switzerland) [3338].

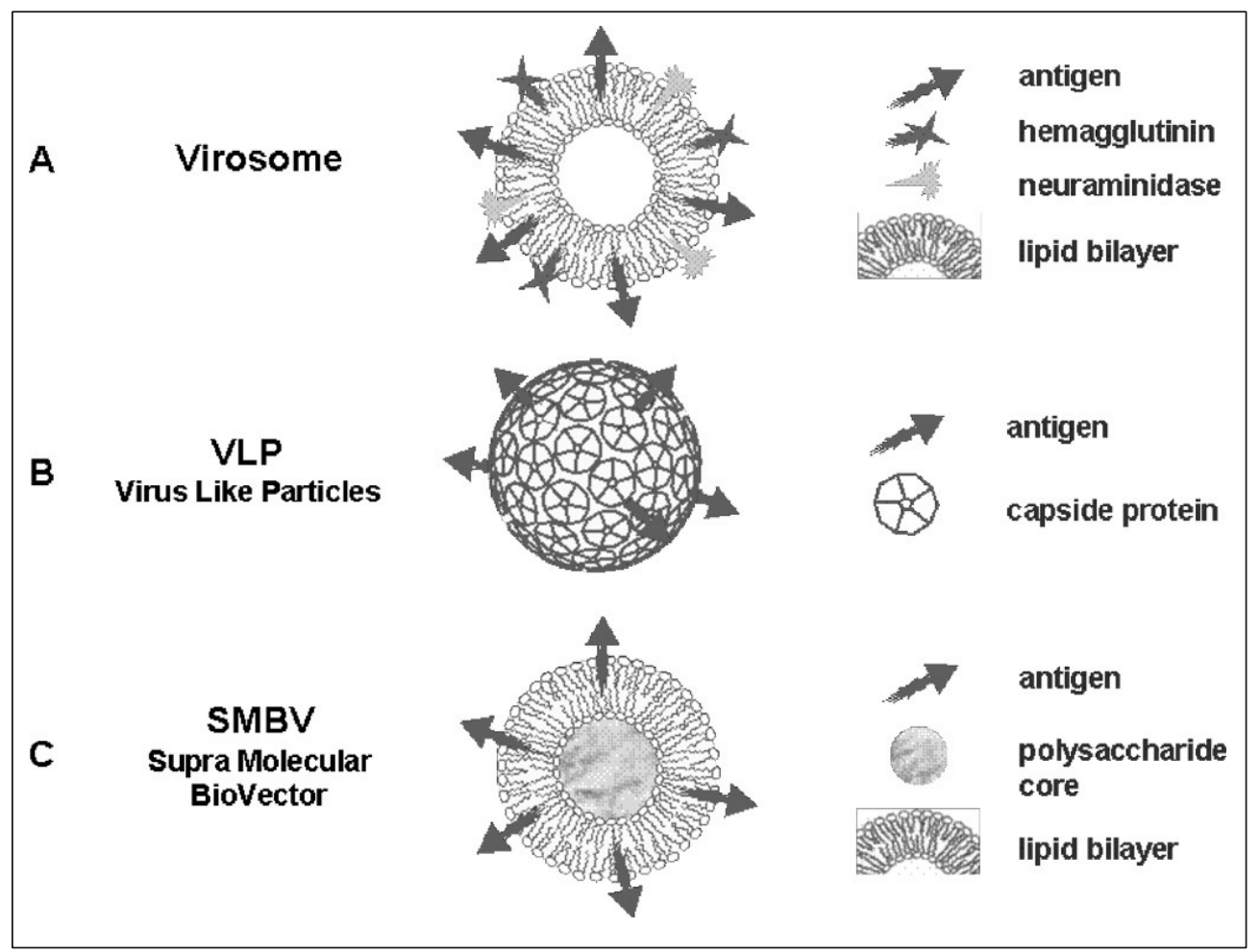

Figure 1 - Composition and structures of biomimetic inspired antigen presenting devices (adapted from [2]).

Virosomes are formidable antigen-presenting devices made of unilamellar lipid vesicles with a mean diameter close to the size of a real virus $(150 \mathrm{~nm})$. Two functional glycoproteins produced by biotechnology are intercalated in the phospholipid bilayer membrane: the influenza hemagglutinin and neuraminidase. They play a key role in the immunoadjuvant properties of Virosomes providing fusion capabilities that enable them to fuse with cell membranes of macrophages and dendritic cells and deliver antigens straight in the cytoplasm of those antigen-presenting cells [37]. The second role of the influenza glycoprotein is to enhance the immune response of the carried antigen because it also promotes opsonization of the Virosomes after administration; hence their uptake by the immune cells $[37,38]$. The method used to prepare Virosomes is based on phospholipid vesicle reconstitution by 
elimination of surfactant from a blend of natural lipids, synthetic lipids, the two glycoproteins and the purified antigen [38]. The antigen provides for specificity of the vaccine (Figure 1A). This method of preparation makes the Virosomes a versatile technology. For instance, antigens can be incorporated in the Virosomes, adsorbed on the surface, or inserted in the lipid bilayer membrane. This allows the influenza vaccine to be yearly formulated using hemagglutinin and neuraminidase as antigens taken from the viral strains recommended by the World Health Organization [37]. Although Virosomes were first proposed in vaccines administered by injections, innovations including this adjuvant also concern the development of vaccine formulation for mucosal routes of administration [39, 40]. Indeed, mucosal immunization represents a promising approach to protecting an individual against infections by neutralizing pathogens at its portal of entry [41]. However, Virosomes appeared unsuitable for mucosal administration, inducing unexplained side effects [33, 39, 42]. Since safety is part of a key issue for prophylactic immunization of healthy individuals, nasal formulations of Virosomes against influenza were quickly withdrawn from the market after several months of clinical use, but the corresponding parenteral vaccines are currently applied each year in large vaccination programs without producing side effects.

The second type of adjuvant built on the basis of a biomimetic methodology is the Virus-Like Particle (VLP) [32, 42-45]. It looks very similar to empty viruses but differs fundamentally from Virosomes in the sense that it results from the reconstitution of a protein viral capside obtained by spontaneous self-assembly of recombinant viral coat proteins (Figure 1B). VLP can be prepared from recombinant proteins arising from various viral strains [32] and using immunogenic epitopes of several pathogens such as the human papilloma virus, Ebola virus, HIV or Hepatitis B [43]. Recently, a human papilloma virus VLP for parenteral administration was approved as a prophylactic vaccine against human papilloma virus infections. It is believed that the immunogenicity of this adjuvant is due to its interactions with dendritic cells that enable the development of both humoral and cellular immunologic response in patients [43].

Another example of antigen-presenting adjuvant built on a biomimetic approach was developed in the late nineties as formulation of mucosal vaccines to be administered by the nasal route. This adjuvant called Supra Molecular Bio-Vector (SMBV) was constituted by a polysaccharide core surrounded by a phospholipidic bilayer in which antigens can be inserted. The diameter of the whole particle, which presented similarities to empty viruses, was in the 50-100 nm range (Figure $1 C$ ). These systems were developed to phase I clinical trials for the nasal vaccination against the influenza viruses. It was demonstrated that the SMBV constituted a platform for the delivery of antigens into cells, while it did not act as an immunomodulator or simple adjuvant. The nasal vaccination with SMBV generated both local mucosal immunity and a systemic cytotoxic T lymphocyte response [46, 47]. Using an antigen from the group $\mathrm{C}$ meningococci, this immunization strategy induced an Immunoglobulin-A mediated bactericidal activity at the mucosal level which can be very effective in fighting the infection at its portal of entry [48]. All data demonstrated the high potential of SMBV for use as nasal delivery for various antigens and further developments are still expected.

Although methods from nanotechnology were introduced as early as the 1970s using liposomes and nanoparticles, the application of these systems was mainly restricted to a simple encapsulation method insuring protection of antigens against degradation by peptidases prior to their uptake by macrophages [49-51]. The introduction of biomimetic approaches in these nanotechnologies made a breakthrough possible, which led to a new generation of antigen-presenting devices to be built on the model of empty viruses and used to formulate prophylactic vaccines which were approved by the authorities. In addition to the opening of an innovative antigen-presenting method, the biomimetic adjuvant suggested so far that it has carrier capability, meaning it can be used to carry and deliver additional compounds to the immune cells [38,52]. For instance, immuno-stimulating agents such as synthetic bacterial CpG oligonucleotides were incorporated into VLP together with the epitope $\mathrm{p33}$ of the lymphatic choriomeningitis virus glycoprotein incorporated as antigen. The whole particle was 
shown to protect mice from viral challenges enhancing the immuno-stimulatory capacity of the antigen and reducing side effects of the CpG oligonucleotides [52].

\section{INTEGRATION OF BIOMIMETIC APPROACHES TO CONTROL THE FATE OF DRUG CARRIERS AFTER INTRAVENOUS ADMINISTRATION}

The introduction of nanotechnology in the formulation of drugs administered by the intravenous route can considerably improve the success of treatments of serious diseases [2]. Such progress can be made possible due to an increase in the precision of the biodistribution of the drug which is then delivered more specifically to targeted organs and cells. The main advantage of using synthetic drug carriers is that they can theoretically be tailor made. Thus, the way they are designed will greatly influence their in vivo fate hence the biodistribution of their cargo. Mechanisms which control the fate of drug carriers administered by the intravenous route involve surface phenomena. They mainly consist in interactions between the drug delivery device outermost layer and components of the biological surrounding medium. For instance, the first event which occurs after intravenous injection of liposomes and nanoparticles is the adsorption of serum proteins [53-56]. This phenomenon is capital for determining whether the drug delivery device will be recognized as a foreign particle by macrophages of the host defense system or whether it will bypass this recognition barrier and remain in the blood [57-61]. In a series of recent works, targeting specificity was suggested to be promoted by enhancing the selective adsorption of some proteins on the drug carrier surface. For instance, a higher tropism for the brain was observed in case of PEG-coated liposomes and nanoparticles due to an increase in the spontaneous adsorption of apolipoprotein-E [62-64]. Thus, it has been suggested that a promising strategy to promote drug carrier specificity could be based on the development of differential protein adsorption capability by modifying the drug carrier surface properties [57]. To achieve this aim, it is necessary to develop drug delivery systems with a wide range of controlled surface properties. A biomimetic approach was suggested to be included in this challenge. It consists in copying the surface structures of living cells such as leukocytes, bacteria and viruses which are able to achieve tissue targeting. In these structures, carbohydrates are highly exposed on the surface and constitute an original bio-addressing and signalization arsenal making communication possible between cells and components of the biological surroundings. The development of a biomimetic approach implying the coating of drug carriers with carbohydrates offers almost infinite possibilities as varied as the carbohydrates in nature [65-75]. However, it requires the development of methods that make easy integration of carbohydrates possible as surface coating material of liposomes and nanoparticles. Indeed, the surface properties of the drug carriers must be easily modulated to obtain the expected protein adsorption pattern, hence the expected targeting specificity of the drug delivery device.

\section{III.1. Preparation of biomimetic drug delivery systems}

Carbohydrate-coated liposomes can be obtained by the incorporation of either natural or synthetic glycolipids in the lipidic composition of liposomes. For nanoparticles, several options were proposed. On the one hand, copolymers can be synthesized by grafting poly(lactideco-glycolide) or poly(ecaprolactone) chains on polysaccharides. After purification, the copolymers are used to formulate nanoparticles by either nanoprecipitation or emulsification-solvent evaporation/ displacement methods [75-77]. On the other, polysaccharide-coated nanoparticles can be synthesized by emulsion polymerization of alkylcyanoacrylate monomers which can be initiated on the polysaccharide chains added to the polymerization medium [69, 74, 78, 79]. In this case, the carbohydrate-coated nanoparticles are formed at the same time as the copolymers. These polymerization methods developed with alkylcyanoacrylates are very interesting. They are versatile and can be applied using various polysaccharides. They can be used to produce a wide range of nanoparticles directly from commercially available compounds in a one pot process $[69,74]$. Playing with the mechanism of the polymerization initiation, i.e. anionic vs. redox radical, nanoparticles with differing spatial arrangement 
of the polysaccharide chains can be generated in a controlled manner. Table / summarizes the different types of nanoparticles coated with polysaccharide chains that can be synthesized. As evidenced in this table, the main difference between the nanoparticles produced by the methods described above results in the spatial arrangement of the polysaccharide chains at the nanoparticle surface depending on the structure of the copolymers. It may be noted that only the nanoparticles with a hairy conformation of the polysaccharide chains are arranged the same way as oligo- and polysaccharides present on the surface of eukaryotic cells and of viruses [80]. In contrast, the nanoparticles coated with polysaccharides arranged as loops and trains display an outermost surface structure which looks more or less like the crosslinked structure of the peptidoglycan found at the surface of Gram + bacteria cells [81].

\section{III.2. Strategy of formulation}

So far, several strategies were followed to formulate biomimetic drug delivery systems. In the first, the use of sialic acids as coating material for nanoparticles and liposomes has been explored. The rationale behind this approach was to obtain long circulating drug delivery carriers capable of escaping the immediate capture by the host defense systems and of enabling distribution of the drug towards various organs by increasing residence time in the bloodstream. In nature, sialic acids play an important role as a biological mask hiding epitopes of antigens exposed on cells. For instance, circulating sialic acid coated red blood cells are not recognized by macrophages. After the sialic acid cover has been removed from the cell surface, they are immediately taken up by macrophages due to very efficient cooperation between the complement and phagocytic systems [82-87].

Table I. Outmost structure of drug carriers designed according to a biomimetic approach and relation with the capacity of the drug carrier to avoid the activation of the complement system (+: activator, non activator, ND: not determined) and the half-life in the blood after intravenous administration. Abbreviations: PLA; poly(lactic acid), PCL: poly(epsilon caprolactone), PACA: poly(alkylcyanoacrylate), PMMA: poly(methylmethacrylate).

\begin{tabular}{|c|c|c|c|c|}
\hline & Coating material & $\begin{array}{l}\text { Nanoparticles } \\
\text { coating structure }\end{array}$ & $\begin{array}{c}\text { Complement } \\
\text { Activation }\end{array}$ & $\begin{array}{l}\text { Half life in blood } \\
\text { after i.v. injection }\end{array}$ \\
\hline \multirow{4}{*}{ 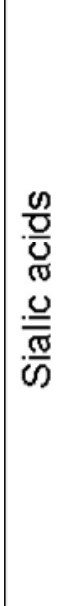 } & $\begin{array}{c}\text { Ganglioside M1 } \\
\text { Ceramide (1 sialic acid) }\end{array}$ & & ND & $\begin{array}{l}\text { Mice: Several hours } \\
\text { Rats: few minutes } \\
\text { [91] }\end{array}$ \\
\hline & $\begin{array}{c}\text { Orosomucoide } \\
\text { Glycoprotein ( } 40 \% \\
\text { carbohydrate, } 18 \text { sialic acid) }\end{array}$ & & $\overline{[99]}$ & Unstable coating \\
\hline & & & ND & $\begin{array}{c}\text { Rats: few minutes } \\
{[76]}\end{array}$ \\
\hline & & & ND & $\begin{array}{c}\text { Rats: several minutes } \\
{[76]}\end{array}$ \\
\hline \multirow{2}{*}{ 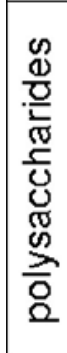 } & $\begin{array}{l}\text { Dextran } \\
\text { Chitosan }\end{array}$ & & $\underset{[69,74,75,99]}{+}$ & $\begin{array}{l}\text { Mice: few minutes } \\
{[78]}\end{array}$ \\
\hline & $\begin{array}{l}\text { Dextran } \\
\text { Chitosan } \\
\text { Dextran sulfate } \\
\text { Heparine }\end{array}$ & $\log ^{2}$ & $\overline{[65,69,74]}$ & $\begin{array}{c}\text { Mice: several hours } \\
{[66]}\end{array}$ \\
\hline
\end{tabular}


By another way, sialic acids are used as surface camouflaging material by extremely virulent bacteria to fool the host defense mechanism. This method helps them bypass the barrier of complement activation and macrophage uptake. It results in severe septicemias in infected patients [88-90]. According to such a biomimetic approach, sialic acids were introduced on the surface of liposomes by incorporating ganglioside M1 (GM1) in the structure of phospholipidic vesicles. The long-circulating capacity of these liposomes was shown to be species dependent. Indeed, long circulating properties in the blood were reported after intravenous injection of GM1-coated liposomes to mice but they were more rapidly removed from the blood stream when injected to rats [91]. Until today, this species dependency has remained unexplained. Concerning nanoparticles, the first sialic acids coating was obtained by adsorbing orosomucoid, a sialic acid-rich glycoprotein, on the surface of poly(alkylcyanoacrylate) nanoparticles. Opsonisation of the nanoparticles was reduced as well as complement activation, but effective duration of the effects was short because the adsorbed orosomucoid was rapidly displaced by other serum proteins resulting from the Vroman effect [92, 93]. Other approaches suggested using poly(sialic acids) as coating material. Lipids coupled with poly(sialic acids) designed to be incorporated in liposomes have been patented but no data about the performance of these new compounds to produce long circulating liposomes were reported in the literature [91]. Poly(sialic acids) coated nanoparticles obtained by the incorporation of a copolymer of poly(sialic acids) and poly(lactic acids) showed a significant longer circulation time of the nanoparticles in the blood after intravenous administration to mice when compared to the corresponding uncoated nanoparticles [76]. The longest circulation time was shown by the nanoparticles on which poly(sialic acid) chains adopted a hair conformation. Many advantages are presented by poly(sialic acids): they are biodegradable and their catabolites, i.e. neuraminic acids, are nontoxic; they are T-independent antigens, i.e. they do not induce immunological memory; and the results obtained with poly(sialic acids) coated nanoparticles were promising. However, works were not continued further. It can be assumed that a major problem in the development of poly(sialic acids) coated drug delivery systems can be the difficulty of producing such a camouflaging material. As mentioned above, poly(sialic acids) are extracted from highly pathogenic bacteria strains. Thus, their production requires the handling of highly pathogenic bacteria which should be cultivated only in safe laboratories, generating a high cost for large-scale production.

Among the other polysaccharides of interest, heparin was proposed as the first line candidate. Heparin is a bioactive polysaccharide produced on a large scale as an anticoagulant drug. Interestingly, heparin is also an inhibitor of the activation of the complement system [9496]. Heparin coated nanoparticles did not induce activation of the complement system $[65,69,73]$ and remained in the bloodstream for long period of time with estimated half-life over $5 \mathrm{~h}$ after intravenous administration to mice [66]. Other polysaccharides extracted from mushrooms were found to inhibit the activation process of complement. They could be included as alternative polysaccharides to produce nanoparticles with a reduced capacity to activate complement [97].

In a more prospective view, several simple polysaccharides were used to modify surface properties of nanoparticles hence the interactions with blood proteins [65-69, 73, 74]. The aim was to develop suitable methods for the production of versatile polysaccharide coated nanoparticles and to investigate how such surface modifications could influence the in vivo fate of the nanoparticles. The polysaccharides used in these still ongoing studies included dextran which is an alpha1-6-poly(glucose), dextran sulfate, a negatively charged derivative of dextran, and chitosan which contains $\mathrm{N}$ acetylglucosamine and deacetylated glucosamine units conferring a net positive charged to the polysaccharide. The results obtained so far have clearly demonstrated that the conformation of the polysaccharide chains present on the nanoparticle surface is one of the key parameters which control complement activation induced by the nanoparticles and opsonisation. The nature of the polysaccharide and the molecular weight were of secondary importance. The charge of the polysaccharides did not show any influence on the complement activation induced by the nanoparticles [70]. For instance, the complement system was systematically activated in human serum in the presence of nanoparticles displaying loops and trains of polysaccharide chains at the surface, as 
this is the case for Sephadex which is a crosslinked dextran and for many bacteria [69, 73-75, 98, 99]. Such nanoparticles are recognized by the host defense systems and rapidly cleared from the bloodstream by macrophages of the mononuclear phagocyte systems. In contrast, nanoparticles displaying polysaccharides in the hairy conformation on their surface can avoid activation of the complement system [65, 69, 73, 74] (Table I). Consequently, a hairy dextran-coated nanoparticle was found to escape the intense capture by the macrophages and remained in the blood stream for several hours [66]. Adsorption of blood proteins on polysaccharide coated nanoparticles was also evaluated in plasma and it was shown that the amount and nature of the adsorbed proteins were modulated by the type, conformation and length of the polysaccharidic coating [73]. Thus, a unique protein adsorption pattern was observed for each type of nanoparticle. This is a very important result in the perspective of developing targeting strategies based on a differential protein-adsorption pattern on nanoparticles.

In the strategies considered above, interactions of nanoparticle surface with blood proteins were controlled by the polysaccharide coating. Although these included important phenomena such as discrimination between stealth and non-stealth systems, it still did not reach the high degree of specificity required to achieve recognition of the drug delivery system by the targeted cells. In nature, carbohydrates directed towards cell receptors are involved in mechanisms of cell regulation and communications either between cells or with the surrounding medium. Thus, several simple carbohydrates including monosaccharides, disaccharides and Lewis carbohydrates directed toward specific receptors were grafted at the surface of liposomes and nanoparticles [100-105]. Satisfactory results were obtained using relevant cell culture models regarding the level of targeting specificity. Convincing results were also obtained in vivo in targeting liposomes and nanoparticles towards hepatocytes after grafting galactose residues at the surface of the drug delivery system [for references see 106]. These results obtained with simple carbohydrates are very encouraging and promise very exciting developments in the future. Indeed, glycobiology is presently a very active field of investigation. It generates considerable results on the resolution of complex structures of carbohydrates and identifying the corresponding biological activities and functionalities. This will eventually contribute to increasing our knowledge in cell communication and therefore help identify new targets and carbohydrate targeting based materials [70-72, 107, 108]. For further prospective, it would seem preferable to attach the ligand receptor, i.e. carbohydrate, as the targeting moiety on the surface of the drug carrier because the targeting strategy will take advantage of differences in the expression level of the targeted receptor according to the cell physiology. Additionally, it would probably be easier to find a relatively universal method to graft various types of carbohydrate on the surface of drug delivery systems in comparison with coupling methods of protein receptors which need to be finely tuned to preserve the functionality of their active site [71]. However, one should keep in mind that biological recognition systems are exquisitely sensitive. For instance, they are capable of differentiating small changes in conformation of carbohydrates in antigen epitopes of pathogens. Thus, a difficulty of the method probably requires that the orientation of the carbohydrate moiety grafted at the surface of the biomimetic drug carrier would be perfectly controlled.

\section{INTEGRATED STIMULI-RESPONSIVE PROPERTIES IN DRUG DELIVERY SYSTEMS}

Delivery of therapeutic molecules such as DNA, RNA and proteins remain an unresolved significant challenge, as entering the cytoplasm of cells without being degraded is highly complicated. Indeed, the first barrier is crossing the outside membrane of a cell. Then such molecules are generally engulfed in early endosomes, trafficking to late endosomes and finally to lysosomes where they are degraded. Virus and pathogens have developed strategies to enhance protein and nucleic acids transport to the cell cytoplasm escaping the lysosomal compartment. They have evolved potent molecular machineries able to sense the lowered $\mathrm{pH}$ gradient of the endosomes and become activated to destabilize the endosomal membrane [109]. Mechanisms developed by viruses were highly used to inspire the 
strategy followed to design drug carriers making possible delivery of DNA and RNA in the cytoplasm of cells. Acid sensitive liposomes were developed first and have been one of the most extensively studied active triggering release strategies so far $[110,111]$. One of the remarkable properties of acid sensitive liposomes is that they become fusogenic at acidic $\mathrm{pH}$ enabling fusion of the liposomal membrane with the endosomal membrane. Consequently, the liposome content is released in the cell cytoplasm avoiding the intense enzymatic metabolisation of the lysosomal compartment $[6,110]$. Although the first generation of $\mathrm{pH}$ sensitive liposomes were leaky in vivo and lost their sensing properties, these problems were solved by formulating liposomes with lipids of high transition temperature and incorporating lipid-polymer conjugates [111, 112]. Interestingly, liposomes formulated with poly(ethylene glycol)-lipid conjugates were additionally less cleared by macrophages and their circulation time in the bloodstream was increased after systemic administration. It was reported that lipid-polymer conjugate liposomes can lose their pH sensitivity. However, in contrast to the previous formulations, it can be restored by incorporating a cleavable bond in the lipid-polymer conjugate so that the polymer moiety of the conjugate can be removed once the liposome has reached the targeted place. This has been obtained using a di-stearoyl glycerol phosphoryl ethanolamine coupled with PEG via a disulfide bond [113].

Several degrees of sophistication can be added to the relatively simple formulations of acid-sensitive liposomes. Peptides having fusogenic properties triggered by an acidic environment were associated with liposomes to deliver the therapeutic cargo in the cell cytoplasm either from the endosomal compartment or directly from the extracellular medium [114].

Development of stimuli-responsive drug carriers is a fast-expanding area. This exciting field of research is boosted by polymer chemistry enabling synthesis of polymeric materials responding to various types of stimuli [115-119]. Stimuli responding polymers have been widely used to formulate controlled drug delivery systems since the early 1990s [120]. Many of them have already been synthesized but the main difficulty is to find components with characteristics suiting the tight constraints imposed by in vivo delivery of drugs. In fact, the polymers must be safe for administration to humans and their responsive characteristics must suit those of the physiological environment in which the drug will be released $[118,121]$. Most pathological processes related to the methods are accompanied by local temperature increase and/or acidosis and hypoxia because of modification of the cell metabolism $[122,123]$. However, the ranges of these physicochemical modifications of the environment conditions are narrow and very precise. For instance, in tumors the local temperature increases by 2 to $5^{\circ} \mathrm{C}$ and/or the $\mathrm{pH}$ decreases by 0.5 to $2.5 \mathrm{pH}$ units (acidosis) when compared to normal tissues. Many of the stimuli responding polymers developed so far respond to modifications in $\mathrm{pH}$ or temperature but only a few are suitable for in vivo applications. Polymers containing poly(amino acids) have been actively developed for this purpose and have shown great promise to be used as stimuli-responsive material suitable for in vivo applications [8, 124-126]. They are now on the front line of the development for various applications in this field. It can also be expected that the new area of the genetically engineered polymers will bring new insight into the development of stimuli-responsive drug carriers in the near future [118, 127-129]. Other stimuli-responsive polymers are sensitive to glutathione or calcium concentration modifications, specific enzymes, ultrasounds or light [118, 130,131]. In general, all these stimuli-responsive polymers undergo sharp conformational modifications in response to changes in their environmental conditions. Stimuli-responsive polymers coupled to lipids or cholesterol are used to sensitize liposomes to various types of stimuli [131-133] (Figure 2). Change in conformation of polymeric chains anchored at the liposome surface destabilized the phospholipidic bilayer in response to the environmental modification. The liposome therefore becomes leaky and releases the encapsulated drug.

The other types of stimuli-responsive drug carriers are formulated with polymers only. Generally, they are obtained by using block copolymers formed with blocks of different nature. Each block is endowed with a defined function in the drug delivery system. Block copolymers synthesized in the purpose of formulating a stimuli-responsive drug carrier are composed of at least one block of stimuli responding 
polymer whose sensitivity will be given to the drug carrier device. Stimuli-responsive drug carriers developed with polymers included mainly polymeric micelles. These systems are formed with amphiphilic block copolymers which self-assemble in aqueous media to form spherical nanoparticles with a core-shell architecture [see for example: 4, 8, 20, 115, 130, 134-136] (Figure 2). Hydrophobic molecules can be entrapped in the hydrophobic core of the polymeric micelles. Copolymers containing ionizable groups can be used to entrap charged therapeutic proteins and peptides or DNA and RNA. A block of PEG is generally included in the copolymer structure to confer stealth properties to the stimuliresponsive polymeric micelles $[4,125]$.

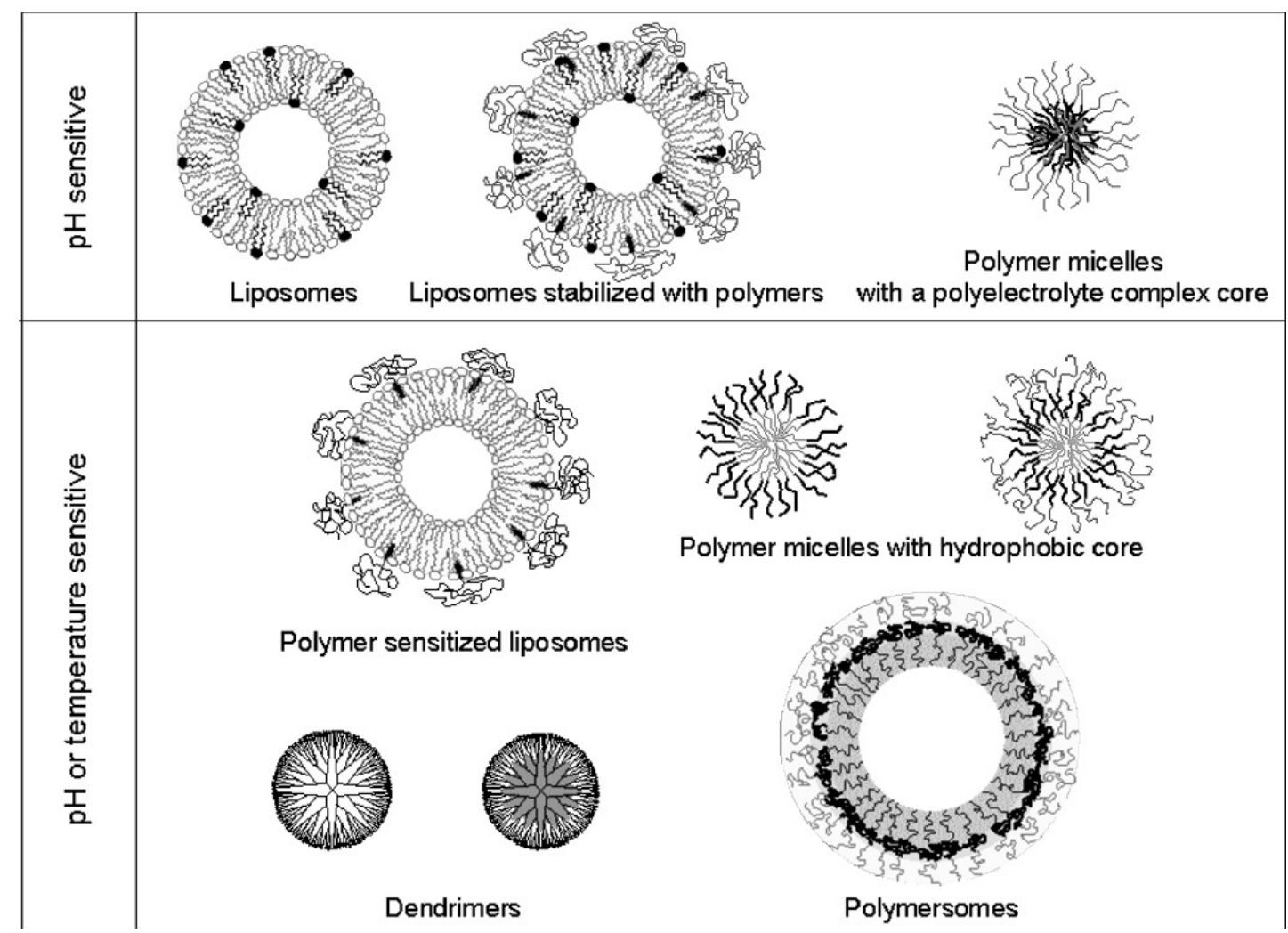

Figure 2 - Structures of $\mathrm{pH}$ and temperature-sensitive drug carriers.

Polymersomes are another type of drug delivery system made by self-assembly of block copolymers. They are a kind of nanocapsule in which the envelope is formed by a single layer of triblock copolymers containing pH or temperature-sensitive sequences [137-140] (Figure 2). In response to modification of the environmental conditions, polymersomes are capable of inverting their structure, resulting in a release of their content. Finally, stimuli responding dendrimers can be described as unimolecular polymeric micelles. They are formed from star-shaped polymers. Their size ranging from 10 to $40 \mathrm{~nm}$ in diameter is much lower than those of the previous objects. They can be sensitized with $\mathrm{pH}$ or temperature-sensitive block copolymers.

Although not all the stimuli-responsive drug carriers made of polymers presented in this review are strictly inspired by a biomimetic approach, they show that polymers can be used as sensor platforms to integrate stimuli-responsive functions in drug carriers. Today, polymers can be tailor made with controlled architecture, leading to almost infinite possibility to synthesize smart polymers $[21,141$ 146]. They can be used to explore new biomimetic strategies in which stimuli responding systems are at the center of biological events, such as those found in the intercellular communication mechanisms involving neurons, mast cells and endocrinal cells [147-150]. They are generally relatively complex and energetic dependent but have in common the fact that an intracellular signal triggers a massive release 
of biochemical mediators in the extracellular medium from secretory granules or vesicles which serve as storage containers. These containers enable transient fusion with the cell membrane under reversible structural changes in response to an external stimulus, including a $\mathrm{pH}$ decrease or a small variation in the concentration in glutathione or ions [147-150]. Although the mechanisms of these biological systems are still incompletely understood, they constitute a basis for future developments of stimuli responding drug carriers based on biomimetic strategies [110-112, 132, 151, 152]. For instance, the recent publication of Broz et al. [153] which described a pH switchable channel-equipped, functional polymer nanocontainer shows these very exciting developments to be promising.

\section{CONCLUSION}

The emergence of new treatments which may involve poorly soluble drugs, easily biodegradable molecules and some drugs endowed with systemic toxicity need highly specific delivery, i.e. targeting. Nanocarriers, including the various types of liposomes, nanoparticles, dendrimers, polymer micelles and polymersomes, are small enough drug delivery devices to serve this purpose. In addition to the usual requirements concerned with drug delivery in humans, they have to be designed in such a way that they can meet with the constraints of the in vivo environments. Together with the improved understanding of the immunological mechanisms and very diverse possibilities in chemistry of polymers and properties of colloids, such nanocarriers can be increasingly tailor made. True targeting requires sophisticated strategies, as delivery of intact drugs such as macromolecular compounds into the cytoplasm of the targeted cells is a complex task. Some bacteria and viruses have acquired such capabilities over centuries of evolution. Mimicking these pathogenic invaders for therapeutic purposes has been progressively developed through the so-called biomimetic strategies. The results obtained in the domain of vaccines are very convincing with already several biomimetic antigen presenting devices on the market. To improve the precision of drug delivery to target cells, development of smart drug carriers capable of delivering their cargo in response to an external stimulus is still in the early stages. However, it can be confidently expected that this nanotechnology will quickly expend taking advantage of the synthesis of stimuli-responding polymers based on biomimetic strategies with perfectly controlled structures and finely tunable properties. The other active area of research concerns the guidance of drug carriers to find their way from the site of administration down to the target site. It has been known for years that sugars and polysaccharides are involved in recognition phenomena, and the introduction of such compounds on the surface of nanocarriers is a promising biomimetic strategy. The results obtained for instance by coating nanoparticles with dextran or chitosan have shown that conformation of the bound polysaccharide on the surface is of prime importance, as nonspecific recognition can be either decreased or increased. As the mechanisms of specific recognition which are probably involved in specific targeting are even more complex, the "magic bullet" of Paul Ehrlich is not yet on the shelf. However, it is no longer merely a pipe dream.

\section{REFERENCES}

1. Allen T.M., Cheng W.W., Hare J.I., Laginha K.M. - Pharmacokinetics and pharmacodynamics of lipidic nano-particles in cancer. - Anticancer Agents Med. Chem., 6, 513-523, 2006.

2. Couvreur P., Vauthier C. - Nanotechnology: intelligent design to treat complex disease. - Pharm. Res., 23, 417-450, 2006.

3. Minko T., Pakunlu R.I., Wang Y., Khandare J.J., Saad M. - New generation of liposomal drugs for cancer. - Anticancer Agents Med. Chem., 6, 537-552, 2006.

4. Nishiyama N., Kataoka K. - Current state, achievements, and future prospects of polymeric micelles as nanocarriers for drug and gene delivery. - Pharmacol. Ther., 112, 630-648, 2006.

5. Toub N., Malvy C., Fattal E., Couvreur P. - Innovative nanotechnologies for the delivery of oligonucleotides and siRNA. Biomed. Pharmacother., 60, 607-620, 2006.

6. Karanth H., Murthy R.S. - pH Sensitive liposomes - Principle and application in cancer therapy. - J. pharm. Pharmacol., 59, 469-483, 2007.

7. Devalapally H., Chakilam A., Amiji M.M. - Role of nanotechnology in pharmaceutical product development. - J. Pharm. Sci., 96, 2547-2565, 2007.

8. Torchilin V.P. - Micellar nanocarriers: pharmaceutical perspectives. - Pharm. Res., 24, 1-16, 2007. 
9. Vauthier C., Couvreur P. - Nanomedicine: a new approach for the treatment of serious diseases. - J. Biomed. Nanotechnol., 3, 223-234, 2007.

10. Van Berkel T.J., Se Smidt P.C., Van Dijk M.C., Giere G.J., Bijsterbosch M.K. - Drug targeting by endogenous transport vehicles. - Biochem. Soc. Trans., 18, 748-750, 1990

11. Rossi L., Serafini S., Pierige F., Antonelli A., Cerasi A., Fraternale A., Chiarantini L., Magnani M. - Erythrocyte-based drug delivery. - Expert Opin. Drug Deliv., 2, 311-322, 2005.

12. Paukner S., Stiedl T., Kudela P., Bizik J., Al Laham F., Lubitz W. - Bacterial ghosts as a novel advanced targeting system for drug and DNA delivery.- Expert Opin. Drug Deliv., 3, 11-22, 2006.

13. Campos S.K., Barry M.A. - Current advances and future challenges in adenoviral vector biology and targeting. - Curr Gene Ther., 7,189-204, 2007.

14. Hamidi M., Zarrin A., Foroozesh M., Mohammadi-Samani

S.- Applications of carrier erythrocytes in delivery of biopharmaceuticals. - J. Control. Release, 118, 145-160, 2007.

15. Riedmann E.M., Kyd J.M., Cripps A.W., Lubitz W. - Bacterial ghosts as adjuvant particles. - Expert Rev. Vaccines, 6, 241253, 2007.

16. Singh M., O'Hagan D.T. - Recent advances in vaccine adjuvants. - Pharm. Res., 19, 715-728, 2002.

17. O'Hagan D.T., Rappuoli R. - Novel approaches to vaccine delivery. - Pharm. Res., 21, 1519-1530, 2004.

18. Wu L.Q., Payne G.F. - Biofabrication: using biological materials and biocatalysts to construct nanostructured assemblies. - Trends Biotechnol., 22, 593-599, 2004.

19. Tu R.S., Tirrell M. - Bottom-up design of biomimetic assemblies. - Adv. Drug Deliv. Rev., 56, 1537-1563, 2004

20. Na K., Sethuraman V.T., Bae Y.H. - Stimuli-sensitive polymeric micelles as anticancer drug carriers. - Anticancer Agents Med. Chem., 6, 525-535, 2006

21. Qiu L.Y., Bae Y.H. - Polymer architecture and drug delivery. - Pharm. Res., 23, 1-30, 2006

22. Torchilin V.P. - Multifunctional nanocarriers. - Adv. Drug Deliv. Rev. - 58, 1532-1555, 2006.

23. Ranney D.F. - Biomimetic transport and rational drug delivery. - Biochem. Pharmacol., 59, 105-114, 2000.

24. Hilt J.Z. - Nanotechnology and biomimetic methods in therapeutics: molecular scale control with some help from nature. - Adv. Drug Deliv. Rev., 56, 1533-1536, 2004.

25. Peppas N.A. - Intelligent therapeutics: biomimetic systems and nanotechnology in drug delivery. - Adv. Drug Deliv. Rev., 56, 1529-1531, 2004.

26. Mandal S., Phadtare S., Sastry M. - Interfacing biology with nanoparticles. - Curr. Applied Phys., 5, 118-127, 2005.

27. Berzofsky J.A., Ahlers J.D., Janik J., Morris J., Oh S., Tarabe M., Belyakov I.M. - Progress on new vaccine strategies against chronic viral infections. - J. Clin. Investig., 114, 450-462, 2004

28. Vajdy M., Srivastava I., Polo J., Donnelly J., O'Hagan D., Singh M. - Mucosal adjuvants and delivery systems for protein,DNA- and RNA-based vaccines. - Immunol. Cell Biol., 82, 616-627, 2004.

29. Aucouturier J., Dupuis L., Ganne V. - Adjuvants designed for veterinary and human vaccines. - Vaccine, 19, 2666-2672, 2001.

30. Jiang Z.H., Koganty R.R - Synthetic vaccines: the role of adjuvants in immune targeting. - Curr. Med. Chem., 10, 14231439, 2003

31. Pawar R., Ben-Ari A. Dom A.J. - protein and peptide parenteral controlled delivery. - Expert opin. Biol. Ther., 4, 12031212, 2004

32. Noad R., Roy P. - Virus-like particles as immunogens. - Trends in Microbiol., 11, 438-444, 2003.

33. Huckriede A., Bungener L., Stegmann T., Daemen T., Medema J., Palache A.M., Wilschut J. - The virosome concept for influenza vaccines. - Vaccine, 23, S1/26-S1/38, 2005

34. Daemen A., Bungener L., Huckriede A., Wilschut J..- Virosomes as an antigen delivery system. - J. Liposome Res., 10, 329-338, 2000.

35. Esposito S., Marchisio P., Bosis S., Lambertini L., Claut L., Faelli N., Bianchi C., Colombo G.L., Principi N. - Clinical and economic impact of influenza vaccination on healthy children aged 2-5 years. - Vaccine, 24, 629-635, 2006.

36. Glück R., Metcalfe I.C.- New technology platforms in the development of vaccines for the future. -Vaccine, 20, B10-B16, 2002.

37. Moser C., Metcalfe I.C., Viret J.F. - Virosomal adjuvanted antigen delivery systems. - Expert Rev. Vaccines, 2, 189-196, 2003.

38. Westerfeld N., Zurbriggen R. - Peptides delivered by immunostimulating reconstituted influenza virosomes. - J. Pept. Sci., 11, 707-712, 2005

39. Gluck U., Gebbers J.O., Gluck R. - Phase 1 evaluation of intranasal virosomal influenza vaccine with and without Escherichia coli heat-labile toxin in adult volunteers. - J. Virol., 73, 7780-7786, 1999.

40. Gluck R.- Intranasal immunization against influenza.- J Aerosol Med., 15, 221-218, 2002b.

41. Holmgren J., Czerkinsky C., Erikssen K., Mharandi A. - Mucosal immunisation and adjuvants: a brief overview of recent advances and challenges. - Vaccine., 21, S89-95, 2003.

42. Mutsch M., Zhou W., Rhodes P., Bopp M., Chen R.T., Linder T., Spyr C., Steffen R. - Use of the inactivated intranasal influenza vaccine and the risk of Bell's palsy in Switzerland. - N. Engl. J. Med., 350, 896-903, 2004.

43. Garcea R.L., Gissmann L. - Virus-like particles as vaccines and vessels for the delivery of small molecules. - Curr. Opin. Biotechnol., 15, 513-517, 2004

44. Grgacic E.V., Anderson D.A. - Virus-like particles: passport to immune recognition. - Methods, 40, 60-65, 2006.

45. Sin J.I. - Human papillomavirus vaccines for the treatment of cervical cancer. - Expert Rev. Vaccines., 5, 783-792, 2006.

46. Von Hoegen P. - Synthetic biomimetic supra molecular Biovector ${ }^{\mathrm{TM}}$ (SMBV ${ }^{\mathrm{TM}}$ ) particles for nasal vaccine delivery. - Adv. Drug Deliv. Rev., 51, 113-125, 2001.

47. Debin A., Kravtzoff R., Vaz Santiago J., Cazales L., Sperandio S., Melber K., Janowicz Z., Betbeder D., Moynier M. Intranasal immunization with recombinant antigens associated with new cationic particles induces strong mucosal as well as systemic antibody and CTL responses. - Vaccine, 20, 2752-2763, 2002. 
48. Baudner B.C., Balland O., Guiliani M.M., Von Hoegen P., Rappuoli R., Betbeder D., Del Giudice G. - Enhancement of protective afficacy following intranasal immunization with vaccine plus a nontoxic LTK63 mutant delivered nanoparticles. - Infect. \& Immunity, 70, 4785-4790, 2002.

49. Kreuter J., Speiser P. - In vitro studies of poly(methylmethacrylate) adjuvants. - J. Pharm. Sci., 65, 1624-1627, 1976.

50. Gregoriadis G. - The immunological adjuvant and vaccine carrier properties of liposomes. - J. Drug Target., 2, 351-356, 1994.

51. Kreuter J. - Nanoparticles as adjuvants for vaccines. - Pharm. Biotechnol., 6, 463-472, 1995.

52. Storni T., Ruedl C., Schwarz K., Schwendener R.A., Renner W.A., Bachmann M.F. - Nonmethylated CG motifs packaged into virus-like particles induce protective cytotoxic T cell responses in the absence of systemic side effects. - J. Immunol., 172, 1777-1785, 2004

53. Brash J.L. - Exploiting the current paradigm of blood-material interactions for the rational design of blood-compatible materials. - J. Biomater. Sci. Polym. Ed., 11, 1135-1146, 2000.

54. Montdargent B., Letourneur D. - Toward new biomaterials. - Infect Control Hosp Epidemiol., 21, 404-410, 2000.

55. Wang Y.X., Robertson J.L., Spillman W.B. Jr, Claus R.O. - Effects of the chemical structure and the surface properties of polymeric biomaterials on their biocompatibility. - Pharm Res., 21, 1362-1373, 2004.

56. Yampolskaya G., Platikanov D. - Proteins at fluid interfaces: Adsorption layers and thin liquid films. - Adv Coll. Interf. Sci., 128-130, 159-183, 2006

57. Muller R.H., Kerck C.M. - Drug delivery to the brain--realization by novel drug carriers. - J. Nanosci. Nanotechnol., 4, 471483, 2004.

58. Owens D.E., Peppas N.A. - Opsonization, biodistribution and pharmacokinetics of polymeric nanoparticles. - Int. J. Pharm., 307, 93-102, 2006.

59. Vonabourg A., Passirani C., Saulnier P., Benoit J.P. - Parameters influencing the stealthiness of colloidal drug delivery systems. - Biomaterials, 27, 4356-4373, 2006.

60. Labarre D., Barratt G., Legrand P., Vauthier C. - Nanoparticles for site specific drug delivery: from concept to clinic. - In: Smart Nanoparticles in Nanomedicine, R. Arshady and K. Kono Eds., Kentus Books, London, 2006, Chap. 2, pp. 37-75.

61. Lynch I., Cedervall T., Lundqvist M., Cabaleiro-Lago C., Linse S., Dawson K.A. - The nanoparticle-protein complex as a biological entity; a complex fluids and surface science challenge for the 21 st century. - Adv. Colloid Interface Sci., 134$135,167-174,2007$.

62. Kreuter J. - Influence of the surface properties on nanoparticlemediated transport of drugs to the brain - J Nanosci Nanotechnol., 4, 484-488, 2004

63. Jones A.R., Shusta E.V. - Blood-brain barrier transport of therapeutics via receptor-mediation. - Pharm. Res., 24, 17591771,2007

64. Kim H.R., Andrieux K., Gil S., Taverna M., Chacun H., Desmaële D., Taran F., Georgin D., Couvreur P. - Translocation of PEGylated nanoparticles into rat brain endothelial cells: role of apolipoproteins on receptor mediated endocytosis. Biomacromolecules, 8, 793-799, 2007.

65. Passirani C., Barratt G., Devissaguet J.P., Labarre D. - Interactions of nanoparticles bearing heparin or dextran covalently bound to poly(methyl methacrylate) with the complement system. - Life Sciences, 62, 775-785, 1998.

66. Passirani C., Barratt G., Devissaguet J.P., Labarre D. - Longcirculating nanoparticles bearing heparin or dextran covalently bound to poly(methyl methacrylate). - Pharm Res, 15, 10461050, 1998.

67. Jaulin N., Appel M., Passirani C., Barratt G., Labarre D. - Reduction of the uptake by a macrophagic cell line of nanoparticles bearing heparin or dextran covalently bound to poly(methyl methacrylate). - J. Drug Targeting, 8, 165-172, 2000.

68. Rouzes C., Gref R., Leonard M., De Sousa Delgado A., Dellacherie E. - Surface modification of poly(lactic acid) nanospheres using hydrophobically modified dextrans as stabilizers in an o/w emulsion/evaporation technique. J.Biomed. Mater. Res., 50, 557-565, 2000.

69. Chauvierre C., Labarre D., Couvreur P., Vauthier C. - Novel polysaccharide-decorated poly(isobutyl cyanoacrylate) nanoparticles. - Pharm. Res., 20, 1786-1793, 2003.

70. Gabius H.-J. - The sugar code in drug delivery. - Adv. Drug Deliv. Rev., 56, 421-424, 2004.

71. Holemann A., Seeberger P. H. - Carbohydrate diversity: synthesis of glycoconjugates and complex carbohydrates. - Curr. Opin. Biotechnol., 15, 615-622, 2004.

72. Ratner D. M., Adams E. W., Disney M. D., Seeberger P. H. - Tools for glycomics: mapping interactions of carbohydrates in biological systems. - Chembiochem: Eur. J. Chem. Biol., 5, 1375-1383, 2004.

73. Labarre D., Vauthier C., Chauvierre C., Petri B., Muller R., Chehimi M.M. - Interactions of blood proteins with poly(isobutylcyanoacrylate) nanoparticles decorated with a polysaccharidic brush. - Biomaterials., 26, 5075-5084 2005.

74. Bertholon I., Vauthier C., Labarre D. - Complement activation by core-shell poly(isobutylcyanoacrylate)-polysaccharide nanoparticles: influences of surface morphology, length, and type of polysaccharide. - Pharm. Res., 23, 1313-1323, 2006.

75. Lemarchand C., Gref R., Passirani C., Garcion E., Petri B., Muller R., Costantini D., Couvreur P. - Influence of polysaccharide coating on the interactions of nanoparticles with biological systems. - Biomaterials, 27, 108-118, 2006.

76. Huve P. - Comprendre et éviter la capture des nanoparticules de poly(acide lactique) par le système des phagocytes mononucléaires. - Ph.D., Université Paris-XI, 1994.

77. Villemson A., Couvreur P., Gillet B., Larionova N.I., Gref R. - Dextran-poly-eta-caprolactone micro- and nanoparticles: preparation, characterization and tamoxifen solubilisation. - J. Drug Deliv. Sci. Technol., 16, 307-313, 2006.

78. Couvreur P., Kante B., Lenaerts V., Deckers-Passau L., Roland M. - Tissue distribution of antitumor drugs associated with polyalkylcyanoacrylate nanoparticules. - J. Pharm. Sci., 69, 199-202, 1980.

79. Douglas S.J., Illum L., Davis S.S. - Particle size and size distribution of poly(butyl 2-cyanoacrylate) nanoparticles. II. Influence of stabilizers. - J. Colloid Interface Sci., 103, 154-163, 1985.

80. Bertozzi C.R., Kiessling L.L. - Chemical glycobiology. - Science, 291, 2357-2364, 2001.

81. Van Heijenoort J. - Formation of the glycan chains in the synthesis of bacterial peptidoglycan. - Glycobiology., 11, 25R36R, 2001. 
82. Jancik J., Schauer R. -. Sialic acid--a determinant of the life-time of rabbit erythrocytes. - Hoppe Seylers Z. Physiol. Chem., 355, 395-400, 1974.

83. Durocher J. R., Payne R. C., Conrad M. E. -. Role of sialic acid in erythrocyte survival. - Blood, 45, 11-20, 1975.

84. Jancik J., Schauer R., Anders K. H., Von Düring M. - Sequestration of neuraminidase-treated erythrocytes. - Cell. Tiss. Res., 186, 209-226, 1978.

85. Schauer R. - Sialic acids and their role as biological masks. - Trends Biochem. Sci., 10, 357-360, 1985.

86. Schauer R. - Sialic acids regulate cellular and molecular recognition. - In: Carbohydrates Synthetic Methods and Applications in Medicinal Chemistry, H. Ogura, A. Hasegawa and T. Suami Eds., Kodansha Ltd, Tokyo, 1992, pp. 340354.

87. Kato Y., Onishi H., Machida Y. - Evaluation of N-succinyl-chitosan as a systemic long-circulating polymer. - Biomaterials, 21, 15791585, 2000

88. Ourth D. D., Bachinski L. M. - Bacterial sialic acid modulates activation of the alternative complement pathway of channel catfish. - Dev. Comp. Immunol., 11, 551-564, 1987.

89. Sakarya S., Oncu S. - Bacterial adhesins and the role of sialic acid in bacterial adhesion. - Med. Sci. Monitor: Int. Med. J. Exp. Clin. Res., 9, RA76-RA82, 2003.

90. Vimr E.R., Kalivoda K.A., Deszo E.L., Steenbergen S.M. - Diversity of microbial sialic acid metabolism. - Microbiol. Mol. Biol. Rev., 68, 132-153, 2004.

91. Gregoriadis G., McCormack B., Wang Z., Lifely R. - Polysialic acids: potential in drug delivery. - FEBS Lett., 315, 271276, 1993.

92. Yamauchi H., Yano T., Kato T., Tanaka I., Nakabayashi S., Higashi K., Miyoshi S., Yamada H. - Effects of sialic acid derivative on long circulation time and tumor concentration of liposomes. - Int. J. Pharm., 113, 141-148, 1995.

93. Olivier J.C., Vauthier C., Taverna M., Puisieux F., Ferrier D., Couvreur P. - Stability of orosomucoid-coated polyisobutylcyanoacrylate nanoparticles in the presence of serum. - J. Control. Release, 40, 157-168, 1996.

94. Kazatchkine M. D., Fearon D. T., Silbert J. E., Austen K. F. - Surface-associated heparin inhibits zymosan-induced activation of the human alternative complement pathway by augmenting the regulatory action of the control proteins on particle-bound C3b. - J. Exp. Med, 150, 1202-1215, 1979.

95. Weber N., Wendel H. P., Ziemer G. - Hemocompatibility of heparin-coated surfaces and the role of selective plasma protein adsorption. - Biomaterials, 23, 429-439, 2002.

96. Keuren J. F., Wielders S. J., Willems G. M., Morra M., Cahalan L., Cahalan P., Lindhout T. - Thrombogenicity of polysaccharidecoated surfaces. - Biomaterials, 24, 1917-1924, 2003.

97. Jeong S. C., Yang B. K., Ra K. S., Wilson M. A., Cho Y., Gu Y. A., Song C. H. - Characteristics of anti-complementary biopolymer extracted from Coriolus versicolor. - Carbohydrate Polymers, 55, 255-263, 2004.

98. Carreno M. P., Maillet F., Labarre D., Jozefowicz M., Kazatchkine M. D. - Specific antibodies enhance Sephadex-induced activation to the alternative pathway in human serum. - Biomaterials, 9, 514-518, 1988.

99. Olivier J.C. - Développement d'un vecteur biomimétique. - Ph.D., Université Paris-XI, 1995

100. Forssen E., Willis M. - Ligand-targeted liposomes.- Adv. Drug Deliv. Rev., 29, 249-271, 1998.

101. Julyan P. J., Seymour L. W., Ferry D. R., Daryani S., Boivin C.

M., Doran J., David M., Anderson D., Christodoulou C., Young A. M. - Preliminary clinical study of the distribution of HPMA copolymers bearing doxorubicin and galactosamine. - J. Control. Release, 57, 281-290, 1999.

102. Sinha V. R., Kumria R. - Polysaccharides in colon-specific drug delivery. - Int. J. Pharm., 224, 19-38, 2001.

103. Ehrhardt C., Kneuer C., Bakowsky U. - Selectins-an emerging target for drug delivery. - Adv. Drug Delivery Rev., 56, 527549, 2004.

104. Nobs L., Buchegger F., Gurny R., Allemann E. - Current methods for attaching targeting ligands to liposomes and nanoparticles.

- J. Pharm. Sci., 93, 1980-1992, 2004.

105. Yamazaki N., Kojima S., Yokoyama H. - Biomedical nanotechnology for active drug delivery systems by applying sugarchain molecular functions. - Curr. Appl. Phys., 5, 112-117, 2005.

106. Barratt G. - Colloidal drug carriers: achievements and perspectives. - Cell. Mol. Life Sci. (CMLS)., 60, 21-37, 2003.

107. Jozefowicz M., Jozefonvicz J. - Randomness and biospecificity: random copolymers are capable of biospecific molecular recognition in living systems. - Biomaterials, 18, 1633-1644, 1997.

108. Barchi J.J. - Emerging roles of carbohydrates and glycomimetics in anticancer drug design. - Curr Pharm Des., 6, 485501,2000

109. Plank C., Oberhauser B., Mechtler K., Koch C., Wagner E. - The influence of endosome-disruptive peptides on gene transfer using synthetic virus-like gene transfer systems. - J. Biol. Chem., 269, 12918-12924, 1994.

110. Fattal E., Couvreur P., Dubernet C. - "Smart" delivery of antisense oligonucleotides by anionic pH-sensitive liposomes. Adv. Drug Deliv. Rev., 56, 931-946, 2004.

111. Andresen T.L. Jensen S.S., Jorgensen K. - Advanced strategies in liposomal cancer therapy: problems and prospects of active and tumor specific drug release. - Prog. Lipid Res., 44, 68-97, 2005.

112. Simoes S., Moreira J.N., Fonseca C., Duzgunes N., de Lima M.C. - On the formulation of pH-sensitive liposomes with long circulation times. - Adv. Drug Deliv. Rev., 56, 947-965, 2004.

113. Kirpotin D., Hong K., Mullah N., Papahadjopoulos D., Zalipsky S. - Liposomes with detachable polymer coating: destabilization and fusion of dioleoylphosphatidylethanolamine vesicles triggered by cleavage of surface-grafted poly(ethylene glycol). - FEBS Lett., 388, 115-118, 1996.

114. Fretz M.M., Mastrobattista E., Koning G.A., Jiskoot W., Storm G. - Strategies for cytosolic delivery of liposomal macromolecules. - Int. J. Pharm., 298, 305-309, 2005.

115. Gaucher G., Dufresne M.H., Sant V.P., Kang N., Maysinger D., Leroux J.C. - Block copolymer micelles: preparation, characterization and application in drug delivery. - J. Control. Release., 109,169-188, 2005.

116. Nakayama M., Okano T., Miyazaki T., Kohori F., Sakai K., Yokoyama M. - Molecular design of biodegradable polymeric micelles for temperature-responsive drug release. - J. Control. Release., 115, 46-56, 2006. 
117. Nakayama M., Okano T. - Intelligent thermoresponsive polymeric micelles for targeted drug delivery. - J. Drug Deliv. Sci. Technol., 16, 35-44, 2006.

118. Kyung K.T., Yin H., Lee E.S., Bae Y.H. - Polymeric nanovehicles for anticancer drugs with triggering release mechanisms. - J. Mater. Chem., 17, 3987-4001, 2007.

119. Rijcken C.J., Soga O., Hennink W.E., van Nostrum C.F. - Triggered destabilisation of polymeric micelles and vesicles by changing polymers polarity: an attractive tool for drug delivery. - J. Control.

Release., 120, 131-148, 2007.

120. Kost J., Langer R. - Responsive polymer systems for controlled delivery of therapeutics. - Trends Biotechnol., 10, 127131, 1992.

121. Portney N.G., Ozkan M. - Nano-oncology: drug delivery, imaging and sensing. - Anal. Bioanal. Chem., 384, 620-630, 2006.

122. Tannock I.F., Rotin D. - Acid pH in tumors and its potential for therapeutic exploitation. - Cancer Res., 49, 4373-4384, 1989.

123. Fukumura D., Jain R.K. - Tumor microenvironment abnormalities: causes, consequences, and strategies to normalize. J. Cell Biochem., 101, 937-949, 2007.

124. Lavasanifar A., Samuel J., Kwon G.S.- Poly(ethylene oxide)block-poly(L-amino acid) micelles for drug delivery. - Adv. Drug Deliv. Rev., 54, 169-190, 2002.

125. Fukushima S., Miyata K., Nishiyama N., Kanayama N., Yamasaki Y., Kataoka K. - PEGylated polyplex micelles from triblock catiomers with spatially ordered layering of condensed pDNA and buffering units for enhanced intracellular gene delivery. - J. Am. Chem. Soc., 127, 2810-2811, 2005.

126. Aliabadi H.M., Lavasanifar A. - Polymeric micelles for drug delivery. - Expert Opin. Drug Deliv., 3, 139-162, 2006.

127. Kopecek J. - Hydrogel biomaterials: a smart future? - Biomaterials, 28, 5185-5192, 2007.

128. Haider M., Megeed Z., Ghandehari H. - Genetically engineered polymers: status and prospects for controlled release. J. Control. Release, 95, 1-26, 2004.

129. Kopecek J. - Smart and genetically engineered biomaterials and drug delivery systems. - Eur. J. Pharm. Sci., 20, 1-16, 2003.

130. Vasir J.K, Reddy M.K., Labhasetwart V.D. - Nanosystems in drug targeting: opportunities and challenges. - Current Nanosci., 1, 47-64, 2007.

131. Paasonen L., Romberg B., Storm G., Yliperttula M., Urtti A., Hennink W.E. - Temperature-sensitive poly(n-(2hydroxypropyl) methacrylamide mono/dilactate)-coated liposomes for triggered contents release. - Bioconjug Chem.,18, 2131-2136, 2007.

132. Kono K. - Thermosensitive polymer-modified liposomes. - Adv. Durg Deliv. Rev., 53, 307-319, 2001.

133. Kono K., Murakami T., Yoshida T., Haba Y., Kanaoka S., Takagishi T., Aoshima S. - Temperature sensitization of liposomes by use of thermosensitive block copolymers synthesized by living cationic polymerization: effect of copolymer chain length. - Bioconjug. Chem., 16, 1367-1374, 2005.

134. Riess G. - Micellization of block copolymers. - Prog. Polym. Sci., 28, 1107-1170, 2003.

135. Letchford K., Burt H. - A review of the formation and classification of amphiphilic block copolymer nanoparticulate structures: micelles, nanospheres, nanocapsules and polymersomes. - Eur. J. Pharm. Biopharm., 65, 259-269, 2007.

136. Sutton D., Nasongkla N., Blanco E., Gao J. - Functionalized micellar systems for cancer targeted drug delivery. - Pharm. Res., 24, 1029-1046, 2007.

137. Chécot F., Lecommandoux S., Klok H. A., Gnanou Y. - From supramolecular polymersomes to stimuli responsive nanocapsules based on poly(diene)-b poly(peptide) diblock copolymers. - Eur.

Phys. J. E., 10, 25-35, 2003.

138. Rodriguez-Hernandez J., Lecommandoux S. - Reversible insideout micellization of pH-responsive and water-soluble vesicles based on polypeptide diblock copolymers. - J. Am. Chem. Soc., 127, 2026-2027, 2005

139. Discher D.E., Ortiz V., Srinivas G., Klein M.L., Kim Y., Christian D., Cai S., Photos P., Ahmed F. - Emerging applications of polymersomes in delivery: From molecular dynamics to shrinkage of tumors. - Prog. Polymer Sci., 32, 838-857, 2007.

140. Rakhmatullina E., Braun T., Chami M., Malinova V., Meier W. - Self-organization behavior of methacrylate-based amphiphilic di- and triblock copolymers. - Langmuir., 23, 12371-12379, 2007.

141. Lee C.C., MacKay J.A., Fréchet J.M., Szoka F.C. - Designing dendrimers for biological applications. - Nat. Biotechnol., 23, 1517-1526, 2005.

142. Braunecker W.A., Matyjaszewski K. - Controlled/living radical polymerization: features, developments, and perspectives. - Prog. Polymer Sci., 33,93-146, 2007.

143. Dimitrov I., Trzebicka B., Müller A.H.E., Dworak A., Tsvetanov C.B. - Thermosensitive water-soluble copolymers with doubly responsive reversibly interacting entities. - Prog. polymer Sci., 32, 1275-1343, 2007.

144. Jeong J.H., Kim S. W., Park T.G. - Molecular design of functional polymers for gene therapy. - Prog. Polymer Sci., 33 , 1239-1274, 2007.

145. Penczek S., Cypryk M., Duda A., Kubisa P., Slomkowski S. - Living ring-opening polymerizations of heterocyclic monomers. - Prog. Polymer Sci., 33, 247-282, 2007.

146. Yokozawa T., Yokoyama A. - Chain-growth polycondensation: The living polymerization process in polycondensation. Prog

Polymer Sci., 33,147-172, 2007

147. Michael D.J., Cai H., Xiong W., Ouyang J., Chow R.H. - Mechanisms of peptide hormone secretion. - Trends Endocrinol. Metab., 17, 408-415, 2006

148. Rutter G.A., Tsuboi T., Ravier M.A. - $\mathrm{Ca}^{2+}$ microdomains and the control of insulin secretion. - Cell. Calcium., 40, 539-551, 2006.

149. Jeftinija S. - The story of cell secretion: events leading to the discovery of the "porosome" - the universal secretory machinery in cells. - J. Cell. Mol. Med., 10, 273-279, 2006

150. Cho S.J., Jena B.P. - Secretory vesicle swelling by atomic force microscopy. - Methods Mol Biol., 319, 317-330, 2006 
151. Peppas N.A., Kim B. - Stimuli sensitive protein delivery systems - J. Drug Deliv. Sci. Technol., 16, 11-18, 2006.

152. Stayton P.S., El-Sayed M.E., Murthy N., Bulmus V., Lackey C., Cheung C., Hoffman A.S. - "Smart" delivery systems for biomolecular therapeutics. - Orthod. Craniofac. Res., 8, 219-225, 2005.

153. Broz P., Driamov S., Ziegler J., Ben-Haim N., Marsch S., Meier W., Hunziker P. - Toward intelligent nanosize bioreactors: a pH-switchable, channel-equipped, functional polymer nanocontainer. - Nano Lett., 6, 2349-2353, 2006. 